\title{
El símbolo del laberinto en Las moradas del castillo interior, de santa Teresa de Jesús
}

\section{The Symbol of the Labyrinth in Las moradas del castillo interior, by santa Teresa de Jesús}

\section{Isabel Hernando Morata}

Universidad de Santiago de Compostela ESPAÑA

isabel_hernando86@hotmail.com

[Hipogrifo, (issn: 2328-1308), 4.2, 2016, pp. 31-41]

Recibido: 11-01-2016/Aceptado: 14-03-2016

DOI: http://dx.doi.org/10.13035/H.2016.04.02.04

Resumen. El castillo de Las moradas de santa Teresa ha despertado el interés de los estudiosos, que han intentado averiguar sus posibles fuentes, y también de algunos artistas, que han ofrecido diversas representaciones gráficas. Este artículo analiza el castillo místico de santa Teresa como laberinto, un símbolo con múltiples valores, sobre todo en la cultura occidental. Este edificio alegórico presenta algunas de las características más destacadas de los laberintos, en concreto de aquellos que solo tienen un camino: la importancia del centro, la dificultad para acceder a él y la transformación del caminante, en este caso el alma humana, hasta la consecución de su meta, la unión con Dios.

Palabras clave. Mística, santa Teresa de Jesús, Las moradas del castillo interior, laberinto.

Abstract. The castle of Las moradas, by santa Teresa, has attracted the attention of scholars, who have tried to guess its sources. Also some artists have been interested on it and have made graphical representations. This article analyses the mystical castle of santa Teresa as a labyrinth, a symbol with different meanings, specially in occidental culture. This allegorical building presents some of the most important characteristics of the labyrinths, specifically those ones with a only path: the significance of the centre, the difficulty of the access to it and the transforma- 
tion of the walker -in this case, the human soul- until the achievement of his goal, the union with God.

Keywords. Mysticism, Santa Teresa de Jesús, Las moradas del castillo interior, Labyrinth.

El castillo de Las moradas constituye uno de los espacios más misteriosos e interesantes de la literatura mística española'. Como es bien sabido, en este tratado santa Teresa explica los grados de oración necesarios para conseguir la unión con Dios. La autora se basa en una alegoría: el castillo con siete moradas en cuyo centro se encuentra Dios representa el alma; a su vez, el alma misma penetra en él y recorre las estancias hasta alcanzar en la última el matrimonio místico. La fortaleza que fundamenta el símil se describe con brevedad al comienzo de la obra: «es considerar nuestra alma como un castillo todo de un diamante u muy claro cristal, adonde hay muchos aposentos, ansí como en el Cielo hay muchas moradas» (I, 1, pp. 211-212) 2. Poco más adelante, se precisa: «Pues consideremos que este castillo tiene, como he dicho, muchas moradas: unas en lo alto, otras en bajo, otras a los lados, y en el centro y mitad de todas estas tiene la más principal, que es adonde pasan las cosas de mucho secreto entre Dios y el alma» (I, 1, p. 213). Las estancias del castillo se disponen no solo en pisos de diferentes alturas, sino también en círculos concéntricos:

No habéis de entender estas moradas una en pos de otra, como cosa enhilada, sino poné los ojos en el centro, que es la pieza u palacio adonde está el Rey, y considerad como un palmito, que para llegar a lo que es de comer tiene muchas coberturas que todo lo sabroso cercan: ansí acá, en rededor de esta pieza están muchas y encima lo mesmo (I, 2, p. 226).

Los estudiosos han intentado dilucidar las fuentes del castillo de siete estancias $^{3}$. Con frecuencia se indica que la imagen procede del evangelio de san Juan, capítulo XIV, versículo 2: «En la casa de mi padre hay muchas moradas»4. Según fray Diego de Yepes, santa Teresa le había revelado que, cuando intentaba averiguar «qué motivo tomaría» para su tratado, Dios le mostró «un globo hermosísimo de cristal, a manera de castillo con siete moradas, y en la sétima, que estaba en el centro, al Rey de la gloria» ${ }^{5}$. La crítica, no obstante, se ha mostrado escéptica

1. La autora de este artículo es beneficiaria de una ayuda para la formación postdoctoral del Plan Gallego de Investigación, Innovación y Crecimiento 2011-2015 (Plan I2C), año 2014, modalidad A, y pertenece al Grupo de Investigación Calderón, dirigido por Santiago Fernández Mosquera, de la Universidad de Santiago de Compostela.

2. Todas las citas siguen la edición Las moradas del castillo interior preparada por Chicharro.

3. Santa Teresa recurre al símbolo de la fortaleza también en los capítulos 18, 20 y 40 del Libro de la vida y en el 3 y 28 de Camino de perfección (Ricard y Pélisson, 1968, pp. 33-35).

4. «In domo Patris mei mansiones multae sunt». El versículo es citado por la mayoría de los investigadores; ver, por ejemplo, p. 212, n. 4 de Las moradas del castillo interior.

5. Fray Diego de Yepes, Vida, virtudes y milagros de la Bienaventurada Virgen Teresa de Jesús; se cita por Chicharro, 1999, p. 64. 
hacia esta supuesta visión ${ }^{6}$. Unamuno propuso que la ciudad amurallada de Ávila inspiró el edificio de Las moradas ${ }^{7}$, mientras Dicken consideró que el verdadero detonante del símbolo teresiano fue el castillo de la Mota en Medina del Campo ${ }^{8}$. Según Menéndez Pidal, en cambio, el referente puede localizarse en las numerosas fortificaciones de los libros de caballerías, que a la santa le gustaba leer en su juventud ${ }^{9}$. Por su parte, Etchegoyen reparó en que en Tercer abecedario espiritual, de fray Francisco de Osuna, obra conocida por santa Teresa, se compara ya el alma con un castillo ${ }^{10}$.

Una perspectiva diferente ofreció Asín Palacios al establecer la similitud entre el castillo de Las moradas y una recopilación de cuentos y pensamientos religiosos de la mística islámica, los Nawādir, datados en el siglo XVI; el paralelismo podía deberse «a reminiscencia subconsciente de relatos orales» ${ }^{11}$. En la misma línea se sitúa López-Baralt, quien señala la impronta en santa Teresa de Abu-I-Hasan alNuri, místico de Bagdad que en el siglo IX escribió Moradas de los corazones ${ }^{12}$. Se han señalado aún otras posibles fuentes: el Castillo de amor, de Jorge Manrique, el tratado médico Remedio de cuerpos humanos y silva de experiencias, del doctor Luis Lobera de Ávila ${ }^{13}$, o L'idea del Theatro, de Giulio Camillo ${ }^{14}$.

Este breve estado de la cuestión revela hasta qué punto el castillo teresiano ha despertado el interés de la crítica. Por otra parte, varios artistas han tratado de representarlo. En 1677 fray Juan de Rojas y Ausa publicó Representaciones de la verdad... sobre las siete moradas de santa Teresa de Jesús... careadas con la noche obscura de... San Juan de la Cruz, que expone el libro teresiano y lo ilustra con dieciséis emblemas de autor anónimo. El primero de ellos presenta el castillo interior como una torre formada por siete mansiones superpuestas; en cada una hay una paloma, que simboliza el alma, la cual se aproxima al sol divino ${ }^{15}$. Un objetivo distinto, puramente ornamental, tiene el estuche donde se guarda el autógrafo de

6. Ricard y Pélisson, 1968, pp. 27-30, refutan la posibilidad de que el relato de Yepes sea cierto.

7. En el artículo «Ávila de los caballeros», recogido en Por tierras de Portugal y de España, p. 126; también expuso esta idea en «Frente a Ávila» (p. 229), «Paisaje teresiano» (p. 239) y «Extramuros de Ávila» (p. 242), recopilados en Andanzas y visiones españolas. Ricard, 1965, apoya la idea de Unamuno, aunque admite que el origen del castillo teresiano puede ser más complejo.

8. Dicken, 1970.

9. Así lo refirió ella misma en el Libro de la vida, p. 54 (capítulo 2). Según Menéndez Pidal, 1942, p. 81, «alguna vez recuerda sus castillos y sus gigantes [los de los libros de caballerías]». Esta tesis defienden también Cuevas, 1982, pp. 90 y ss., y Márquez Villanueva, 1983, pp. 499-500.

10. Etchegoyen, 1923, p. 333.

11. Asín Palacios, 1946, p. 272

12. López-Baralt, 2010.

13. Ambos por Márquez Villanueva, 1983, pp. 501-512.

14. Carrión, 1994, pp. 256-258. También se ha apuntado la relación de Las moradas con las representaciones gráficas y diagramas empleados por los predicadores (R. de la Flor, 1995, pp. 239-240). Chorpenning, 1979, p. 123, enmarca Las moradas en la tradición de los símbolos arquitectónicos de los escritos teológicos. Según Egido, 2010, p. 84, el lugar imaginario de Las moradas tiene una función mnemotécnica, en la línea de las Confesiones de san Agustín.

15. Los grabados son descritos y comentados en Herrero García, 1945. Swietlicki, 1988, p. 37, detecta «a significant number of differences between her textual imagery [de santa Teresa] and Roxa's graphic 
Las moradas en el convento de san José de las religiosas carmelitas descalzas de Sevilla ${ }^{16}$. Del castillo solo se representa la muralla -que recuerda a la de Ávila- y, en la parte superior de la caja, el diamante del que está construido. Más compleja es la imagen de frey Paschal of the Blessed Sacrament, quien se decanta por siete círculos concéntricos para simbolizar las moradas ${ }^{17}$. La última plasmación artística de la que se tiene noticia es la maqueta diseñada en 1981 por Gordon Wagner. En un panfleto salido a la luz el año siguiente se publicaron numerosas fotografías, dibujos y comentarios de esta construcción. Como en el grabado de la obra de fray Juan de Rojas, el castillo se ha convertido en una torre de siete pisos, aunque ahora son circulares ${ }^{18}$.

Ninguna de estas figuraciones parece aprehender con exactitud la arquitectura de la fortaleza mística teresiana. Como ha observado Swietlicki, «Admittedly, the creation of illustrations for any text is a problematic undertaking: an artist must attempt to transform the written word into a concrete image ${ }^{19}$. También Márquez Villanueva repara en que el castillo de Las moradas es «un símil por completo intelectualizado, no previsto para su realización plástica» y detecta con perspicacia qué impide su plasmación artística: la superposición de las nociones de horizontalidad y verticalidad, pues no es posible «compaginar la imagen de una torre cilíndrica de cristal diamantino con la disposición concéntrica de las moradas en un corte sagital ${ }^{20}$.

La complejidad de este edificio alegórico es evidente ${ }^{21}$. Santa Teresa insiste en la multiplicidad de habitaciones por las que puede transitar el alma, así como en su confusa distribución: «Déjela andar [al alma] por estas moradas [segundas] arriba y abajo y a los lados» (I, 2, p. 227); «no consideren pocas piezas, sino un millón» $(\mathrm{l}, 2$, p. 229). El intrincado diseño garantiza que el camino del alma hasta el centro sea difícil e incierto. Por este motivo, se ha hablado de «labyrinthine quality of Teresa's mystical path», «labyrinthine layers», «castle-labyrinth» ${ }^{22}$, y de «cierto aire laberíntico» ${ }^{23}$. Hasta ahora, solo tales alusiones sugieren la relación de Las mora-

imagery» y reproduce el primer grabado -es decir, el castillo o torre- (p. 39), el primero de las moradas primeras y el segundo de las segundas (p. 43).

16. En la edición de Castillo interior o Las moradas preparada por Rodríguez, p. 33, se muestra una fotografía del estuche.

17. Paschal of the Blessed Sacrament, 1962, p. 568.

18. Wagner, 1982.

19. Swietlicki, 1988, p. 37.

20. Márquez Villanueva, 1983, p. 498; ver también la nota 15 de esa página.

21. Además, la última morada, donde se encuentra Dios, es un palacio dentro del castillo: «poné los ojos en el centro, que es la pieza u palacio adonde está el Rey» (I, 2, p. 226). Hatzfeld, 1969, p. 42, llega a dudar de si el edificio de Las moradas es en realidad un castillo. García de la Concha, 1978, p. 266, considera que la planta de la fortaleza se corresponde con la de una iglesia, mientras que solo el centro tiene esta forma para Egido, 2010, p. 108.

22. Swietlicki, 1988, p. 38.

23. Carrión, 1994, p. 248; insiste en esta noción: «esa unión consigo misma [de santa Teresa] sin espacio ni tiempo concreto que ella opta por representar en un laberinto textual con forma de castillo» (p. 281) También Santarcangeli, 1997, p. 176, nombra el palacio de las siete estancias de Teresa de Ávila en su fundamental estudio sobre los laberintos. 
das con este símbolo. Tal vez un análisis del castillo interior como laberinto permita comprender mejor su estructura y finalidad.

Como se sabe, el laberinto es un elemento constructivo y artístico con una importancia destacada para la cultura occidental. En Europa su historia se inicia con el mito de Teseo y el Minotauro, representado en algunos mosaicos romanos ${ }^{24}$. De estos proceden, muy probablemente, los laberintos de los pavimentos de las iglesias cristianas ${ }^{25}$. El más antiguo conocido se encuentra en la basílica de san Reparato en Chlef -antes Orléansville (Algeria)-, datada en siglo IV²6. También se diseñaron laberintos en los suelos de iglesias y catedrales construidas en la Edad Media en Italia y Francia, como los de santa Maria in Trastevere, en Roma, la catedral de Chartres y la catedral de Amiens. Una de las finalidades que se atribuyen a estos pavimentos es recordar al cristiano la dificultad de su camino hasta el encuentro con Dios ${ }^{27}$. También se les asocia la función protectora de mantener alejados a los malos espíritus, que algunos historiadores adjudican ya a los pavimentos romanos $^{28}$. Incluso se ha afirmado que permitían realizar una fingida peregrinación hacia Jerusalén, representada por el centro, a aquellos que debido a enfermedad o pobreza no podían emprender el viaje real ${ }^{29}$.

El laberinto posee, por tanto, importantes valores simbólicos en el arte cristiano. En Las moradas, varios aspectos permiten relacionar el castillo interior con este tipo de imágenes. Conviene aclarar que la relación se establece aquí con los llamados «laberintos unicursales», aquellos en los que solo hay un camino, aunque con numerosas vueltas hasta el centro, mientras que en los «multicursales» a veces el caminante debe decantarse entre varias vías ${ }^{30}$. Pues bien, el centro es la parte más importante de los unicursales: «en él está la justificación y la consumación, el sentido y la causa, la lógica profunda del signo» ${ }^{37}$. En el tratado místico de santa

24. Sobre los laberintos de los mosaicos romanos, puede verse Matthews, 1922, pp. 46-51, y Santarcangeli, 1997, pp. 207-222.

25. Matthews, 1922, p. 54, y Becker, 1996, p. 181.

26. Sobre el laberinto de la iglesia de san Reparato, puede verse Matthews, 1922, p. 54, y Santarcangeli, 1997, pp. 232-234.

27. «The Christian journey is well symbolized by the actual layout of the Christian labyrinth [...] finally reaching the centre which is the union with God» (Pennick, 1986, p. 17). Santarcangeli, 1997, pp. 56-57, observa que uno de los valores universales del laberinto - no solo el de las iglesias cristianas- es «recordarle al hombre sus extravíos a lo largo del camino de la vida o bien la dificultad de hallar la salvación eterna o la Jerusalén celeste». Ver también Matthews, 1922, p. 58.

28. «ll a une fonction religieuse de défense contre les assauts du mal» (Chevalier y Gheerbrant, 1990, p. 55). Ver también Alonso Garzón, 2014, pp. 44 y 55. Los historiadores han ofrecido más significados, entre ellos las desviaciones del cristiano que cae en el pecado y se aparta del recto camino de la fe; ver Matthews, 1922, pp. 66-67; Santarcangeli, 1997, pp. 68-69, y Méndez Filesi, pp. 157-173.

29. Santarcangeli, 1997, pp. 68-69.

30. En inglés existe una palabra para cada uno de estos conceptos: labyrinth para los unicursales y maze para los multicursales. Los laberintos unicursales son considerados «seudolaberintos» por Santarcangeli, 1997, p. 53.

31. Santarcangeli, 1997, p. 175, quien generaliza esta afirmación para todo tipo de laberintos. Sin embargo, en algunos multicursales no hay centro, y el objetivo de quien penetra en ellos es solo encontrar la salida. 
Teresa, en el centro se encuentra Dios, y de ahí emana la luz y el agua que llegan a las demás moradas (VII, 2, pp. 438-439). Acceder al centro del laberinto es siempre complicado; como indica Chiari:

Parcourir les entrelacs de bout en bout n'est jamais facile: à un moment donné, l'expérience finit par provoquer un sentiment de peine. II s'agit donc d’une épreuve qui fait momentanément, ou définitivement, sortir le sujet de son état normal. Pénétrer les circonvolutions, c'est aussi subir une métamorphose ${ }^{32}$.

Santa Teresa enfatiza que pocas almas llegan a la séptima estancia: «Mas anque acá [en las moradas segundas] tenga muchos [vasallos] el rey de la tierra, no entran todos hasta su cámara» (III, 1, p. 254); a medida que se avanza hacia el interior del castillo, son menos las almas que prosiguen su camino: se insiste en el sufrimiento del alma en su peregrinar: «iOh, válame Dios, y qué son los trabajos interiores y esteriores que padece hasta que entra en la sétima morada!» (VI, 1, p. 335); exclama santa Teresa: «Oh, válame Dios, Señor, cómo apretáis a vuestros amadores, mas todo es poco para lo que les dáis después!» (VI, 11, p. 421). El camino resulta, por tanto, una prueba para quien lo emprende, que sufre y se transforma en su progreso hacia el centro ${ }^{33}$.

Las «sabandijas y bestias que están en el cerco del castillo» (I, 1, pp. 216-217) - los vicios y pasiones mundanas - penetran en las primeras moradas, pero ya en las cuartas «pocas veces entran las cosas ponzoñosas» (IV, 1, p. 270) y, en las quintas, «no hay tanto lugar para entrar las cosas emponzoñosas, unas lagartijillas sí, que, como son agudas, por doquiera se meten» $(V, 1$, p. 303). Ya se ha indicado que uno de los valores que podían presentar los laberintos de las iglesias era la protección frente a los malos espíritus. Pero no por ello ha de descuidarse el alma en ningún momento, porque el demonio «debe tener en cada una [de las piezas] muchas legiones de demonios para combatir que [las almas] no pasen de unas a otras» (II, 1, p. 239). El alma siempre está en peligro de regresar a las primeras moradas; avisa santa Teresa: «no dejará de ir creciendo si no torna atrás ya a hacer ofensas de Dios, porque entonces todo se pierde, por subida que esté un alma en la cumbre» (IV, 3, p. 294). Otra peculiaridad del edificio teresiano permite relacionarlo con el símbolo del laberinto: el misterio y la incertidumbre con que se mueve el caminante ${ }^{34}$. La autora se refiere a las «moradas secretas del castillo» (I, 2, p. 231), a los «secretos caminos» (IV, 3, p. 291) y avisa de que «Su Majestad os dará por otros

32. Chiari, 2010, p. 25.

33. "C'est que [...] le labyrinthe doit à la fois permettre l'accès au "centre" para un sorte de "voyage" initiatique, et l'interdire à ceux qui ne sont pas qualifiés» (Chevalier y Gheerbrant, 1990, p. 554). Sobre el símbolo del centro en Las moradas, ver Izquierdo Sorli, 1993, pp. 105-115.

34. Egido, 2010, p. 101, señala una tesis básica del tratado teresiano: su relación con la peregrinación, concepto apropiado para la expresión de la vivencia mística (Ewer, 1933, p. 59). Sobre el símbolo del camino en Las moradas, ver Izquierdo Sorli, 1993, pp. 93-99. La representación del alma como un peregrino que recorre un laberinto hasta su unión con Dios fue empleada por el jesuita belga Hermann Hugo en su libro Pia Desideria, de 1624 (Méndez Filesi, 2009, p. 255). 
caminos lo que os quita por este, por lo que Su Majestad sabe, que son muy ocultos sus secretos» (III, 2, p. 265) ${ }^{35}$.

Santa Teresa explica con detalle los pasos que se siguen hasta llegar al centro: «la puerta para entrar en este castillo es la oración» (I, 1, p. 217); para ingresar en las segundas moradas, el alma debe «dar de mano a las cosas y negocios no necesarios» (I, 2, p. 230); en las moradas cuartas, explica cómo es la «oración de recogimiento» (IV, 3, pp. 287-297), mientras que en las quintas se practica la «oración de unión» (V, 2-4, pp. 309-331). Sin embargo, la posibilidad de seguir hacia el interior no depende del alma sino de Dios, pues es Él quien la lleva de una morada a otra y permite finalmente el matrimonio espiritual: «verán cómo Su Majestad le lleva de unas moradas a otras» (II, 1, p. 244). En el epílogo insiste: «Verdad es que no en todas las moradas podréis entrar por vuestras fuerzas, anque os parezca las tenéis grandes, si no os mete el mesmo Señor del castillo» (p. 461). Para ello el alma ha de abandonar sus sentidos - que, en la alegoría, equivalen a la gente del castillo- y potencias - los alcaides, mayordomos y maestresalas (I, 2, p. 223)-:

Su Majestad nos ha de meter y entrar Él en el centro de nuestra alma, y para mostrar sus maravillas mejor no quiere que tengamos en esta más parte de la voluntad, que del todo se le ha rendido, ni que se le abra la puerta de las potencias y sentidos, que todos están dormidos, sino entrar en el centro del alma sin ninguna $(\mathrm{V}, 1, \mathrm{p} .308)$

Aún se puede afinar más la relación del edificio místico teresiano con este símbolo: el laberinto llamado «clásico», cuyo origen se encuentra en las monedas de Cnosos de los siglos IV-II a.C., está formado también por siete pasillos concéntri$\cos ^{36}$. Este tipo de laberinto, que pervivió con variantes durante siglos ${ }^{37}$, se vincula con la concepción pre copernicana del universo, que, como es sabido, situaba a la tierra en el centro y a los demás astros girando en órbitas circulares a su alrededor ${ }^{38}$. Santa Teresa parece revelar en Las moradas el vínculo entre tal teoría y su castillo alegórico: «en metiendo el Señor a el alma en esta morada suya, que es el centro de la mesma alma, ansí como dicen que el cielo impíreo adonde está Nuestro Señor no se mueve como los demás, ansí parece no hay los movimientos en esta alma»

35. El castillo de santa Teresa presenta todas las características que, según Matthews, 1922, p. 183, definen al laberinto: es un artificio, se ha diseñado con un propósito, existe cierto grado de complejidad en su trazado, sus partes están comunicadas, es decir, el camino es continuo, y hay comunicación entre el interior y el exterior. También cumple los criterios señalados por Chiari, 2010, pp. 24-25. Además, según Santarcangeli, 1997, p. 176, «la progresión hacia el centro, hacia la adquisición del saber, hacia el encuentro con el "misterium magnum", suele realizarse en fases bien definidas».

36. Ver, por ejemplo, Pennick, 1986, p. 3, y Santarcangeli, 1997, p. 97.

37. Santarcangeli, 1997, p. 226, refiere que en la Edad Media: «el dibujo convencional del laberinto tiene siete vueltas».

38. «The classical labyrinth pattern, which is the form of the vast majority of carved and boulder labyrinths, has seven circuits [...] The geocentric Western tradition of pre-copernican cosmology tells of seven spherical envelopes that pass above the Earth [...] Each of the rings of the classical labyrinth is related to one of the planetary spheres, and hence to a day of the week» (Pennick, 1990, p. 48). Ver también Méndez Filesi, 2009, pp. 149-151. 
(VII, 2, p. 440). Aunque no reproduce fielmente el modelo pre copernicano, la autora recoge la idea de que una parte del universo es fija mientras que el resto se mueve. No es necesario explicar, por otra parte, el valor simbólico del número siete; basta recordar su importancia en La subida al monte Carmelo, de san Juan de la Cruz ${ }^{39}$.

Santa Teresa emplea una vez la palabra «laberinto» en Las moradas, aunque no para referirse al intrincado camino que debe recorrer el alma sino a la decoración de los jardines que hay en el interior del castillo: «Aunque no se trata de más de siete moradas, en cada una de estas hay muchas: en lo bajo y alto y a los lados, con lindos jardines, y fuentes, y laborintios, y cosas tan deleitosas, que desearéis deshaceros en alabanzas del gran Dios» (Epílogo, pp. 461-462) ${ }^{40}$. Este tipo de laberintos alcanzaron gran popularidad a partir del siglo XVI como ornamentación de los vergeles. Por ejemplo, Carlos V mandó levantar uno en el Alcázar de Sevilla, en el jardín de la Cruz. En esta época, estos artificiosos caminos carecían ya del valor religioso y espiritual que los había caracterizado en las centurias anteriores ${ }^{41}$. Se habían convertido en un «símbolo de estatus. No todo el mundo puede permitirse un gran jardín en el cual hay un laberinto ${ }^{42}$. La autora los equipara a las fuentes y otras «cosas tan deleitosas», es decir, su función es embellecer las estancias del castillo interior. Aquí se ha tratado de mostrar cómo la arquitectura alegórica de santa Teresa se relaciona con la imagen del laberinto. La multiplicidad y complejidad de los espacios, la importancia del centro, la alusión a los «caminos secretos» y las dificultades que ha de sobrellevar el alma en el recorrido permiten considerar este castillo interior como laberinto, símbolo con profusión de significados en la cultura cristiana.

\section{BIBLIOGRAFÍA}

Alonso Garzón, Fernando Segismundo, Laberintos. Tradición viva, Siero (Asturias), Sapere Aude, 2014.

Asín Palacios, Miguel, «El símil de los castillos y moradas del alma en la mística islámica y en Santa Teresa», Al-Ándalus, 1, 1946, pp. 263-274.

39. «On remarquera que saint Jean de la Croix parle de siete mansiones, que correspondent aux sept degrés d'amour, et qu'il parle aussi du primer aposento de amor (Subida del Monte Carmelo, LIV. II, ch. 11)» (Ricard y Pélisson, 1968, p. 38, n. 31).

40. La palabra «laborintios» aparece en el autógrafo entre líneas, según indica Chicharro, p. 462, n. 4, que anota: «deformación vulgar, con distorsión vocálica y epéntesis, por laberintos». Pero la forma «laborintio» usan fray Luis de Granada en su Manual de oraciones y espirituales ejercicios (Obras completas. Tomo III, p. 264) y Gaspar Gómez de Toledo en la Tercera parte de la tragicomedia Celestina, p. 172. El editor de esta última, Barrick, señala (p. 483, nota 610): «Though the modern form is "laberinto", Covarrubias gives "laberintio". "Laborintio" is not unknown elshwere (e.g., santa Teresa, Las moradas [...]), and is apparently based by popular etymology on "labor"». Efectivamente, Covarrubias emplea el término «laberintio», e indica «Fray Lorenzo de Zamora, en su Monarquía mística le pareció haber dicho "laborintio", "quasi labor intus"; al sonido parece cuadrarle, pero consta por lo dicho que no es este su origen [sino la palabra latina "labyrinthus"]». Ver también Lida de Malkiel, 1984, pp. 261-262, quien remite a Faral, 1923, p. 39.

41. Santarcangeli, 1997, p. 249; sobre este tipo de laberintos, ver pp. 274-293.

42. Alonso Garzón, 2014, p. 144 
Becker, Udo, Enciclopedia de los símbolos, trad. José Antonio Bravo, Barcelona, Robinbook, 1996.

Carrión, María M., Arquitectura y cuerpo en la figura autorial de Teresa de Jesús, Madrid, Anthropos, 1994.

Chevalier, Jean y Alain Gheerbrant, Dictionnaire des Symboles, Paris, Robert Laffont/Jupiter, 1990.

Chiari, Sophie, L'image du labyrinthe à la Renaissance, Détours et arabesques au temps de Shakespeare, Paris, Honoré Champion, 2010.

Chicharro, Dámaso, «Introducción», en Teresa de Jesús, Las moradas del castillo interior, ed. Dámaso Chicharro, Madrid, Biblioteca Nueva, 2015, pp. 9-147.

Chorpenning, Joseph, «The Literary and Theological Method of The Interior Castle», Journal of Hispanic Philology, 3, 1979, pp. 121-133.

Covarrubias Orozco, Sebastián de, Tesoro de la lengua castellana o española, ed. Ignacio Arellano y Rafael Zafra, Madrid/Pamplona/Frankfurt am Main, Iberoamericana/Universidad de Navarra/Vervuert, 2006.

Cuevas García, Cristóbal, «El significante alegórico en el Castillo teresiano», Letras de Deusto, 12, 1982, pp. 77-97.

Dicken, Trueman, «The Imagery of the Interior Castle and its Implications», Ephemerides Carmelitacae, 21, 1970, pp. 198-218.

Egido, Aurora, «La configuración alegórica de El castillo interior», en El águila y la tela. Estudios sobre Santa Teresa de Jesús y San Juan de la Cruz, Palma, José J. de Olañeta y Universitat de les Illes Balears, 2010, pp. 79-110.

Etchegoyen, Gaston, L'amour divin. Essai sur les sources de Sainte Thérèse, Bordeaux/Paris, Feret et fils/E. de Boccard, 1923.

Ewer, Mary Anita, A Survey of Mystical Symbolism, London, Society for Promoting Christian Knowledge, 1933.

Faral, Edmon, Les arts poétiques du XIle et du XIIIe siècle, Paris, Honoré Champion, 1923.

García de la Concha, Víctor, El arte literario de Santa Teresa, Barcelona, Ariel, 1978.

Gómez de Toledo, Gaspar, Tercera parte de la tragicomedia de Celestina, ed. Mac E. Barrick, Philadelphia, University of Pennsylvania Press, 1973.

Granada, fray Luis de, Obras completas. Tomo III. Manual de oraciones y espirituales ejercicios, ed. Álvaro Huerga, Madrid, Fundación Universitaria Española/ Dominicos de Andalucía, 1994.

Hatzfeld, Helmut A., Santa Teresa de Ávila, New York, Twayne Publishers, 1969.

Herrero García, Miguel, «El grabado al servicio de la mística», Revista de ideas estéticas, 11, 1945, pp. 59-67. 
Izquierdo Sorli, Montserrat, Teresa de Jesús, una aventura interior. Estudio de un símbolo, Ávila, Institución Gran Duque de Alba de la Excma. Diputación Provincial, 1993.

Lida de Malkiel, M. ${ }^{\text {a }}$ Rosa, Juan de Mena. Poeta del prerrenacimiento español, México, El Colegio de México, 1984.

López-Baralt, Luce, «Teresa of Jesús and Islam: the Simile of the Seven Concentric Castles of the Soul», en A New Companion to Hispanic Mysticism, ed. Hilaire Kallendorf, Leiden/Boston, Brill, 2010, pp. 175-199.

Márquez Villanueva, Francisco, «El símil del castillo interior: sentido y génesis», en Congreso Internacional Teresiano, ed. Teófanes Egido Martínez, Víctor García de la Concha y Olegario González de Cardedal, Salamanca, Universidad de Salamanca, 1983, vol. 2, pp. 495-522.

Matthews, William H., Mazes and Labyrinths. A General Account of Their History and Developments, New York/Toronto, etc., Longmans/Green and Co., 1922.

Méndez Filesi, Marcos, El laberinto. Historia y mito, Barcelona, Alba, 2009.

Menéndez Pidal, Ramón, La lengua de Cristóbal Colón. El estilo de Santa Teresa y otros estudios sobre el siglo XVI, Buenos Aires/México, Espasa Calpe, 1942.

Paschal of the Blessed Sacrament, «A Visual Aid to the Interior Castle», Ephemerides Carmelitacae, 13, 1962, pp. 566-575.

Pennick, Nigel, Labyrinths. Their geomancy and symbolism, Lugar y editorial desconocidos, 1986 [1. . edición: Cambridge, Runestaff, 1984].

Pennick, Nigel, Mazes and Labyrinths, London, Robert Hale, 1990.

R. De la Flor, Fernando, Emblemas. Lecturas de la imagen simbólica, Madrid, Alianza, 1995.

Ricard, Robert, «Le symbolisme du "château intérieur" chez Sainte-Thérèse», Bulletin Hispanique, 67, 1965, pp. 25-41.

Ricard, Robert y Nicole Pélisson, Études sur Sainte Thérèse, Paris, Centre de Recherches Hispaniques, 1968.

Santarcangeli, Paolo, El libro de los laberintos, trad. César Palma, Madrid, Siruela, 1997.

Swietlicki, Catherine, «The Problematic Iconography of Teresa of Ávila's Interior Castle», Spanish Mysticism. Studia Mystica, 11, 1988, pp. 37-47.

Teresa de Jesús, santa, Castillo interior o Las moradas, ed. José Vicente Rodríguez, Madrid, Espiritualidad, 1989.

Teresa de Jesús, santa, Las moradas del castillo interior, ed. Dámaso Chicharro, Madrid, Biblioteca Nueva, 2015a. 
Teresa de Jesús, santa, Libro de la vida, ed. Jorge García López, Madrid, Penguin clásicos, $2015 b$.

Unamuno, Miguel de, Andanzas y visiones españolas, Madrid, Espasa-Calpe, 1975 [décima edición].

Unamuno, Miguel de, Por tierras de Portugal y de España, Buenos Aires, EspasaCalpe Argentina, 1941.

Wagner, Gordon y Virginia, The Castle of the Seven Dwelling Places, Pasadena (California), The Castle Press, 1982. 
